\title{
Serotonin Depletion in the Adult Rat Causes Loss of the Dendritic Marker MAP-2 A New Animal Model of Schizophrenia?
}

\author{
P.M. Whitaker-Azmitia, Ph.D., A. Borella, B.Sc., and N. Raio, B.Sc.
}

Many trophic factors are now thought to also function in maintenance of the adult brain. We hypothesized that since serotonin plays a role in synaptogenesis, it may also function in maintenance of synapses in the adult. Adult rats were depleted of serotonin with the tryptophan hydroxylase inhibitor p-chlorophenylalanine (PCPA) for
10 days. Fourteen days after the final treatment, immunodensitometry showed a significant decrease in the synaptic marker, MAP-2. Our results are discussed in respect to the recent finding of decreased MAP-2 staining in postmortem schizophrenic brains.

[Neuropsychopharmacology 12:269-272, 1995]
KEY WORDS: Serotonin; Schizophrenia; PCPA;

Hippocampus; MAP-2

In addition to its action as a neurotransmitter, serotonin plays an important role in the development of the mammalian brain (Lauder 1990; Whitaker-Azmitia 1991); and in particular may influence synaptogenesis (Chubakov et al. 1986). At least part of the effect that serotonin exerts on immature target regions is elicited through the 5- $\mathrm{HT}_{1 \mathrm{a}}$ receptor-linked release of the neurotrophic factor S-100 $\beta$ from astroglial cells (WhitakerAzmitia et al. 1990).

Recently, it has become evident that many aspects of development are still present in the adult brain and may play a role in maintaining brain structures such as dendrites. Specifically, for the serotonin system, the $5-\mathrm{HT}_{1 \mathrm{a}}$ receptor in mature brain is still found on astroglial cells and is still capable of releasing S-100 $\beta$ (Azmitia and Whitaker-Azmitia 1991; Whitaker-Azmitia et

From the Department of Psychiatry and Behavioral Science, State University of New York at Stony Brook, NY 11794.

Address correspondence to: P.M. Whitaker-Azmitia, Department of Psychiatry and Behavioral Science, State University of New York at Stony Brook, NY 11794.

Received June 9, 1994; revised October 13, 1994; accepted October $14,1994$. al. 1993). In addition, removal of serotonin in the adult brain leads to a loss of S-100 $\beta$ (Haring et al. 1993) and of synapses (Chen et al. 1994). Thus, depletion of serotonin in the adult rat brain may lead to a loss of a number of markers of synaptic integrity. One such marker is MAP-2, a microtubule associated protein (MAP) found largely in dendrites. MAP-2 stimulates microtubule formation and cross-links microtubules to cytoskeletal elements, thus stabilizing cell components such as dendrites. It has often been used as a marker of dendritic damage or plasticity, particularly in the hippocampus (Johnson and Jope 1992). Interestingly, this marker has recently been found to be decreased in postmortem schizophrenic brain (Arnold et al. 1991).

\section{METHOD}

Five male Sprague-Dawley rats weighing 150 to $175 \mathrm{~g}$ were injected intraperitoneally with the tryptophan hydroxylase inhibitor parachlorophenylalanine (PCPA) as follows: $300 \mathrm{mg} / \mathrm{kg}$ a day for 2 days, followed by 100 $\mathrm{mg} / \mathrm{kg}$ every other day for four additional doses (i.e., 8 days). This inhibitor will decrease serotonin content to less than $10 \%$ of normal levels without altering serotonin terminal density (Dewar et al. 1992). Five control animals were injected with a comparable volume of sa- 
A

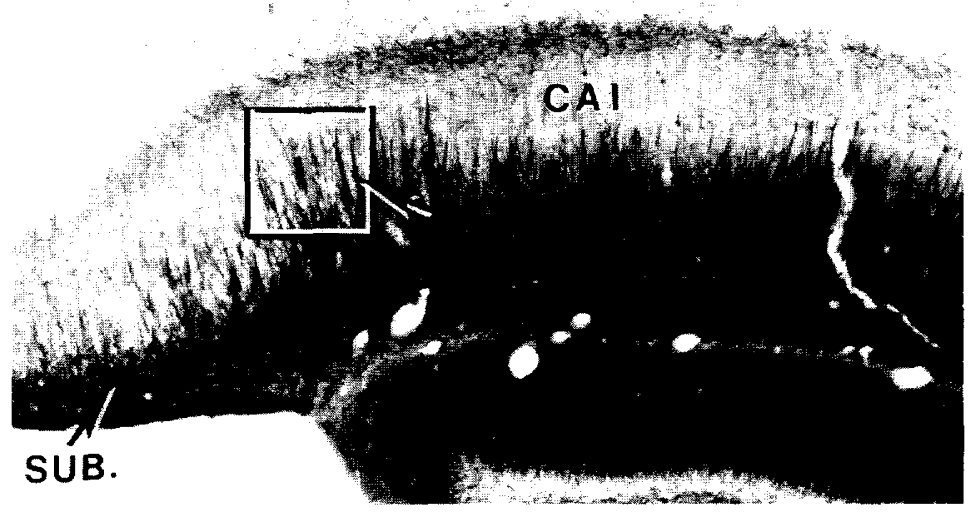

C

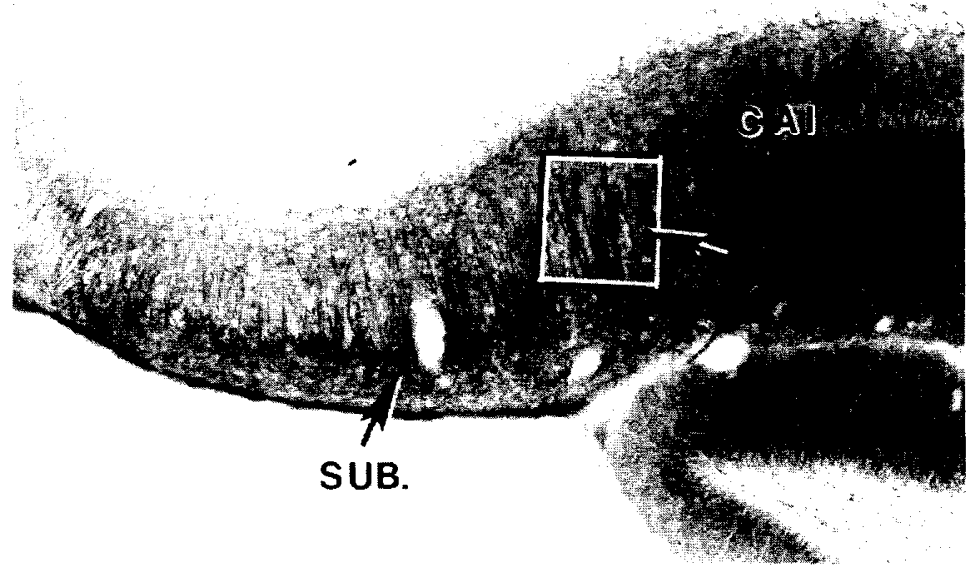

Figure 1. Representative photomicrographs of MAP-2 immunostaining of adult rat hippocampus treated with saline (A and B) or PCPA $(C$ and $D)$. The area outlined in $A$ and $C(\times 40)$ is shown in higher power magnification $(\times 400)$ in $\mathbf{B}$ and $D$. Key: Sub.: subiculum.
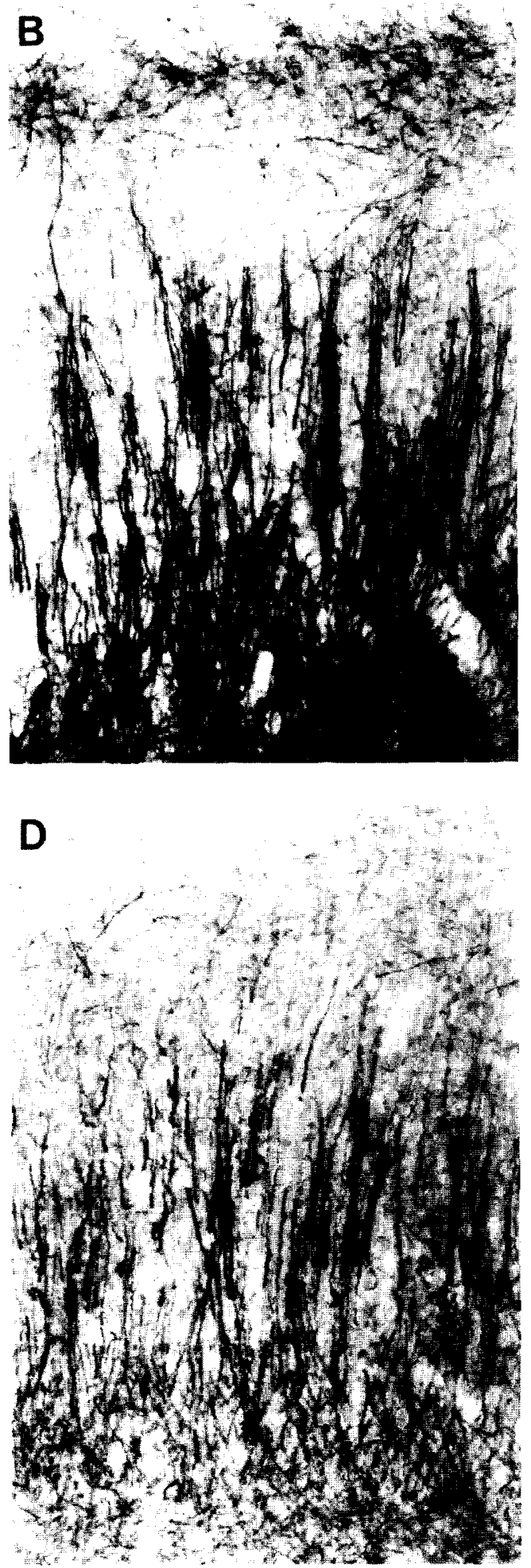

line. Fourteen days after the final injection, rats were anesthetized with a ketamine/rompun mixture and perfused with $4 \%$ paraformaldehyde in phosphatebuffered saline (PBS), pH 7.4 at $5^{\circ} \mathrm{C}$ at a rate of 100 $\mathrm{ml} /$ minute for 3 minutes and then at $25 \mathrm{ml} /$ minute. The brain was postfixed 1 hour in $4 \%$ paraformaldehyde fol- lowed by 24 hours in $20 \%$ sucrose and sectioned at 30 $\mu \mathrm{m}$ on a freezing microtome before incubation overnight at $4{ }^{\circ} \mathrm{C}$ with anti-MAP-2 (mouse monoclonal diluted $1 / 500$ in PBX containing $0.3 \%$ Triton-X-100 and $0.3 \%$ normal goat serum). The sections were visualized using the Avidin-Biotin ( $\mathrm{ABC}$ stain; Vector Labs.) pro- 
cedure with diamino-benzidine (DAB:0.005\%) as the substrate with $0.02 \%$ water. A region underneath the pyramidal neurons of the subiculum (stratum radiatum) depicted in the boxes shown in Figure $1 \mathrm{~A}$ and $1 \mathrm{C}$ was analyzed by image analysis densitometry using the microcomputer image device (MCID) system by Imaging Research (St. Catherines, Ontario). At least five sections from each of the five animals in the two treatment groups were measured.

\section{RESULTS}

Serotonin depletion caused a significant loss of MAP-2 staining throughout the brain, but most noticeably throughout the hippocampal formation. In particular, the subiculum and $C A_{1}$ regions were affected by the treatment (Figure 1).

Image analysis of the subiculum region showed a significant loss of MAP-2 staining $(p<.02)$. In control animals the relative optical density of MAP-2 staining was $0.324+0.010$ relative optical density units (ROD). In PCPA-treated animals, staining intensity was $0.261+0.014$ ROD.

\section{DISCUSSION}

Our results clearly show a loss of MAP-2 staining in the adult rat after depletion of serotonin with the tryptophan hydroxylase inhibitor PCPA. This observation has many interesting implications.

First, in view of the recent finding of a loss of MAP-2 immunostaining in postmortem schizophrenia brain, our findings have obvious implications for the understanding of the brain processes that may result in this disease. Central information processing may be dependent on the formation of new synapses and the formation of such synapses is highly dependent on the incorporation of tubulin into microtubules. This process of incorporation is stimulated by MAP-2. Lack of staining indicates that new synapse formation has not, or perhaps cannot, take place.

The possible involvement of serotonin in schizophrenia has long been an issue that becomes more relevant with the suggestion that serotonin plays a role in stabilizing the cytoskeleton of cells (Van Woerkom 1990) and that the cellular cytoskeleton is disturbed in schizophrenia (Arnold et al. 1991). Moreover, at least three studies have correlated decreased serotonin in the cerebrospinal fluid of schizophrenics with decreased brain volume (Losonczy et al. 1986; Nyback et al. 1983; Potkin et al. 1983). Finally, the method of serotonin depletion that we have chosen (i.e., PCPA) is known to produce deficits in latent inhibition in rats. Latent inhibition deficits are considered to be one of the most valid behavioral models of schizophrenia. Indeed, it has been suggested that latent inhibition can be due to decreased serotonin in hippocampus leading to the disruption of the subicular projection to the nucleus accumbens (Feldon and Weiner 1992). Thus, our findings may have behavioral validation as a model of schizophrenia as well.

Our results also have implications for the developmental hypothesis of schizophrenia. One of the main components of this hypothesis is the lack of gliosis in postmortem schizophrenic brain in spite of the pronounced morphological changes (Pilowsky et al. 1993). However, in our model we have produced morphological changes in an adult animal by a means that does not produce gliosis (Haring et al. 1993) and that may indeed prevent gliosis (Sharma et al. 1993).

Our observations need not necessarily be limited to a model of schizophrenia. Many other disorders linked to lack of serotonin, such as depression or impulse disorders, may also be associated with a loss of synaptic MAP-2 staining. However, to date, only brains of schizophrenics have been subjected to postmortem analysis of MAP-2 staining.

In conclusion, we have produced morphological changes in an adult rat that resemble changes seen in postmortem schizophrenic brain. Our findings could be further explored as a potential animal model of schizophrenia.

\section{ACKNOWLEDGMENTS}

The authors are grateful to Efrain Azmitia for helpful suggestions and to the National Institute on Aging for research funding.

\section{REFERENCES}

Arnold SE, Lee VM, Gur RE, Trojanowski JQ (1991): Abnormal expression of two microtubule associated proteins (MAP2 and MAP5) in specific subfields of the hippocampal formation in schizophrenia. Proc Natl Acad Sci USA 88:10850-10854

Azmitia EC, Whitaker-Azmitia PM (1991): Awakening the sleeping giant: Anatomy and plasticity of the brain serotonergic system. J Clin Psychiatry 52:4-16

Chen L, Hamaguchi K, Ogawa M, Hamada S, Okada N (1994): PCPA reduces both monoaminergic afferents and nonmonoaminergic synapses in the cerebral cortex. Neurosci Res 19:111-115

Chubakov AR, Gromova EA, Konovalov GV, Sakisova EF, Chumasov EI (1986): The effects of serotonin on the morphofunctional development of rat cerebral cortex in tissue culture. Brain Res 369:285-289

Dewar KM, Grondin L, Carli M, Lima L, Reader TA (1992): [3]H-Paroxetine binding and serotonin content of rat cortical areas, hippocampus, neostriatum, ventral mesencephalic tegmentum and midbrain raphe nuclei region 
following p-chlorophenylalanine and p-chloroamphetamine treatment. J Neurochem 58:250-258

Feldon J, Weiner I (1992): From an animal model of an attentional deficit towards new insights into the pathophysiology of schizophrenia. J Psychiatr Res 26:345-366

Haring JH, Hagan A, Olson J, Rodgers B (1993): Hippocampal serotonin levels influence the expression of $S-100 \beta$ detected by immunocytochemistry. Brain Res 631:119123

Johnson GVW, Jope RS (1992): The role of microtubule associated protein-2 (MAP-2) in neuronal growth, plasticity and degeneration. J Neurosci Res 33:505-512

Lauder JM (1990): Ontogeny of the serotonergic system in the rat: Serotonin as a developmental signal. Ann NY Acad Sci 600:297-308

Losonczy MF, Song IS, Mohs RC, Mathe AA, Davidson M, Davis BM, Davis KL (1986): Correlates of lateral ventricular size in chronic schizophrenia, II. Biological measures. Am J Psychiatry 143:1113-1118

Nyback H, Berggren BM, Hindmarsh T, Sedvall G, Wiesel FA (1983): Cerebroventricular size and cerebrospinal fluid monoamine metabolites in schizophrenia patients and healthy volunteers. Psychiatr Res 9:301-308

Pilowsky LS, Kerwin RW, Murray RM (1993): Schizophrenia: A neurodevelopmental perspective. Neuropsychopharmacology 9:83-91
Potkin SG, Weinberger DR, Linnoila M, Wyatt RJ (1983): Low CSF 5-hydroxyindoleacetic acid in schizophrenic patients with enlarged cerebral ventricles. Am J Psychiatry 140:21-25

Sharma HS, Olsson Y, Cervos-Navarro J (1993): P-chlorophenylalanine, a serotonin synthesis inhibitor, reduces the response of glial fibrillary acidic protein induced by trauma to the spinal cord. An immunohistochemical investigation in the rat. Acta Neuropathol (Berl) 86(5): 422-427

Van Woerkom AE (1990): The major hallucinogens and the central cytoskeleton: An association beyond coincidence? Towards subcellular mechanisms in schizophrenia. Medical Hypotheses 31:7-15

Whitaker-Azmitia PM (1991): Role of serotonin and other neurotransmitter receptors in brain development: Basis for developmental pharmacology. Pharmacol Rev 43:533-561

Whitaker-Azmitia PM, Murphy R, Azmitia EC (1990): S-100 protein is released from astroglial cells by stimulation of $5-\mathrm{HT}_{1 \mathrm{a}}$ receptors and regulates development of serotonin neurons. Brain Res 528:155-159

Whitaker-Azmitia PM, Clarke C, Azmitia, EC (1993): Localization of $5-\mathrm{HT}_{1 \mathrm{a}}$ receptors to astroglial cells in adult rats: Implications for neuronal-glial interactions and psychoactive drug mechanism of action. Synapse 14:201-205 